\title{
Monitoring of the bacterial and fungal biodiversity and dynamics during Massa Medicata Fermentata fermentation
}

\author{
Yun Xu • Yan-Bo Xie • Xin-Ran Zhang • Chen Chen • \\ Hongyu Xiang • Qiuhong Xie
}

Received: 12 July 2013 /Revised: 7 August 2013 / Accepted: 10 August 2013 /Published online: 28 August 2013

(C) The Author(s) 2013. This article is published with open access at Springerlink.com

\begin{abstract}
The microbial community dynamics play an important role during Massa Medicata Fermentata (MMF) fermentation. In this study, bacterial and fungal communities were investigated based on the culture-dependent method and polymerase chain reaction-denaturing gradient gel electrophoresis analysis. Meanwhile the dynamic changes of digestive enzyme activities were also examined. Plating results showed that MMF fermentation comprised two stages: pre-fermentation stage ( $0-4$ days) was dominated by bacterial community and post-fermentation stage (5-9 days) was dominated by fungal community. The amount of bacteria reached the highest copy number $1.2 \times 10^{10} \mathrm{CFU} / \mathrm{g}$ at day 2 , but the fungi counts reached $6.3 \times 10^{5} \mathrm{CFU} / \mathrm{g}$ at day 9 . A total of 170 isolates were closely related to genera Enterobacter, Klebsiella, Acinetobacter, Pseudomonas, Mucor, Saccharomyces, Rhodotorula, and Amylomyces. DGGE analysis showed a clear reduction of bacterial and fungal diversity during fermentation, and the dominant microbes belonged to genera Enterobacter, Pediococcus, Pseudomonas, Mucor, and Saccharomyces. Digestive enzyme assay showed filter paper activity; the activities of amylase, carboxymethyl cellulase, and lipase reached a peak at day 4; and the protease activity constantly increased until the end of the fermentation. In this study, we carried out a detailed
\end{abstract}

\footnotetext{
Y. Xu $\cdot$ X.-R. Zhang $\cdot$ C. Chen $\cdot$ H. Xiang $\cdot$ Q. Xie

National Engineering Laboratory for AIDS Vaccine, School of Life

Sciences, Jilin University, Changchun 130012, China
}

Y. Xu $\cdot$ X.-R. Zhang $\cdot$ C. Chen $\cdot$ H. Xiang $(\varangle) \cdot$ Q. Xie $(\square)$

Key Laboratory for Molecular Enzymology and Engineering of

Ministry of Education, School of Life Sciences, Jilin University,

Changchun 130012, China

e-mail: hyxiang@jlu.edu.cn

e-mail: qhxie@jlu.edu.cn

\section{Y.-B. Xie}

School of Life Sciences, Jilin Agricultural University,

Changchun 130033, China and comprehensive analysis of microbial communities as well as four digestive enzymes' activities during MMF fermentation process. The monitoring of bacterial and fungal biodiversity and dynamics during MMF fermentation has significant potential for controlling the fermentation process.

Keywords Massa Medicata Fermentata fermentation . PCR-DGGE · Digestive enzyme · Bacterial community · Fungal community

\section{Introduction}

Massa Medicata Fermentata (MMF) is also known as Liu Shenqu; it is one of the most widely used traditional fermented Chinese medicines and is also one of the earliest medicines recorded in Chinese Pharmacopoeia. In the clinic, it is mainly useful for indigestion, vomiting, diarrhea, and other symptoms caused by poor diet (Tao 2000). The fermentation of MMF is a spontaneous process, whose composition consists of five traditional Chinese medicinal materials (red bean, bitter almond, Artemisia annua, Xanthium sibiricum, and Polygonum hydropiper), flour, and wheat bran. Different microbes coexisting in this fermentation process can produce a variety of digestive enzymes, which can decompose higher molecular compounds and transform them into some new smaller functional substances that are beneficial to be absorbed by the human body such as glycosides, essential oils, vitamins, small peptides, and so on (Gao and Jia 2002). The biotransformation can greatly enhance the efficacy and reduce some side effects of the medicine (Wu et al. 2013). At present, it has become a hot topic in medicinal microbe fermentation and transformation of traditional Chinese medicine $(\mathrm{Wu}$ et al. 2013). Thus, it is necessary to investigate the digestive enzymes as well as the microbial diversity during MMF fermentation process. 
So far, the digestive enzyme researches were mainly about amylase and protease (Wang et al. 2012). The microbial researches are mainly based on conventional culture-dependent methods (Gao and Jia 2002; Hu et al. 2004). And these approaches consist of isolating and enumerating microbial groups by growing them on different selective media and identifying the isolates by using phenotypic and molecular techniques. Although plate counting can provide quantitative data, the conventional culture-dependent methods are time consuming because of long culture periods. Also, it is known that only a small proportion of microorganisms can be cultured, and this often results in an incomplete representation of the true microbial diversity present (Hugenholtz et al. 1998). In recent years, culture-independent methods which are based on molecular biology techniques allowed for a rapid analysis of the microorganism diversity and dynamics during fermentation without culturing, such as polymerase chain reaction-denaturing gradient gel electrophoresis (PCRDGGE), restricted fragment length polymorphisms, and single-strand conformation polymorphism. PCR-DGGE analysis was widely used to analyze the microflora in various traditional fermented products, such as Chinese liquor Daqus (Wang et al. 2011), Japanese shochu (Endo and Okada 2005), Portuguese fermented sausage (Albano et al. 2008), Italian cheese (Fontana et al. 2010), and so on.

Plenty of data have been published regarding microbes, and digestive enzyme activities were mainly about commercial MMF (Zhang et al. 2012a). However, there is little information about the dynamic changes of bacterial and fungal communities and four digestive enzymes' (amylase, protease, cellulase, and lipase) activities during MMF fermentation process. In this study, we sought to fill these gaps by exploring the microbiota, combining both PCR-DGGE technology and cultivation-dependent methods as well as monitoring the activity dynamics of the four digestive enzymes during MMF fermentation process. To our knowledge, this is the first report about the microbiota of MMF during fermentation process using PCR-DGGE analysis. The dynamics monitoring of the microbiota and digestive enzymes' activities during MMF fermentation has significant potential for controlling MMF fermentation.

\section{Materials and methods}

The fermentation of MMF and sample collection

Under laboratory conditions, the MMF fermentation was performed. Each raw material was firstly crushed by a grinder; then $100 \mathrm{~g}$ of $A$. апnиа, $100 \mathrm{~g}$ of $P$. hydropiper, and $100 \mathrm{~g}$ of $X$. sibiricum were mixed with the appropriate water, boiled for $1 \mathrm{~h}$, and finally mixed with $500 \mathrm{~g}$ of flour, $20 \mathrm{~g}$ of red bean, $20 \mathrm{~g}$ of bitter almond, and 1,000 $\mathrm{g}$ of wheat bran. The mixture was shaped in small boxes, then incubated at around $30-37^{\circ} \mathrm{C}$ and $70-80 \%$ of the humidity for about 9 days. The samples were collected every $24 \mathrm{~h}$ for measurement of digestive enzymes' activities and analysis of microflora.

\section{Digestive enzyme assay}

Five-gram samples were suspended in $12.5 \mathrm{~mL}$ of the appropriate buffer and mildly agitated at $4{ }^{\circ} \mathrm{C}$ overnight. The samples were centrifuged at $10,000 \times g$ at $4{ }^{\circ} \mathrm{C}$ for $30 \mathrm{~min}$, and the supernatant was collected for the digestive enzyme assay. All tests were carried out in triplicate.

Amylase activity was assayed by the dinitrosalicylic acid (DNS) method of Miller (1959) with slight modifications, using $1 \%$ starch solution in $0.1 \mathrm{M}$ phosphate buffer (pH 6.5) containing $17 \mathrm{mM} \mathrm{NaCl}$ as a substrate. The substrate solution $(350 \mu \mathrm{L})$ and $50 \mu \mathrm{L}$ of enzyme solution were incubated at $37^{\circ} \mathrm{C}$ for $15 \mathrm{~min}$; then $50 \mu \mathrm{L}$ of $2 \mathrm{M} \mathrm{NaOH}$ was added to stop the reaction. Fifty microliters of the DNS reagent was added to the reaction solution and incubated in a boiling water bath for $5 \mathrm{~min}$; absorbance values at $540 \mathrm{~nm}$ were measured. Blanks contained phosphate buffer instead of a digestive enzyme solution. One unit of amylase activity (U/g MMF) was defined as the amount of enzyme required for the liberation of $1 \mu \mathrm{mol}$ of maltose per minute under the described conditions.

Protease activity was determined according to Sigma's nonspecific protease activity assay using $0.65 \%(w / v)$ casein solution in $50 \mathrm{mM}$ potassium phosphate buffer $(\mathrm{pH} 7.0)$ as a substrate. Of the enzyme solution, $0.5 \mathrm{~mL}$ was mixed with $2.5 \mathrm{~mL}$ of casein solution and incubated at $37{ }^{\circ} \mathrm{C}$ for $10 \mathrm{~min}$, and then $2.5 \mathrm{~mL}$ of trichloroacetic acid reagent was added and incubated at $37{ }^{\circ} \mathrm{C}$ for $30 \mathrm{~min}$ to stop the reaction. The samples were centrifuged at $12,000 \times g$ for $5 \mathrm{~min}$. One milliliter of supernatant was mixed with $2.5 \mathrm{~mL}$ of $500 \mathrm{mM}$ $\mathrm{Na}_{2} \mathrm{CO}_{3}$, and $0.5 \mathrm{~mL}$ of Folin's reagent was added immediately. The mixture was incubated at $37{ }^{\circ} \mathrm{C}$ for $30 \mathrm{~min}$. Absorbance at $660 \mathrm{~nm}$ was measured. Blanks contained phosphate buffer instead of digestive enzyme solution. One unit of protease activity (U/g MMF) was defined as the amount of enzyme required for the liberation of $1 \mu \mathrm{g}$ of tyrosine per minute under the described conditions.

Cellulase activities were determined according to the method described by Ghose (1987) using carboxymethyl cellulose sodium and Whatman no. 1 filter paper in $50 \mathrm{mM}$ citrate buffer ( $\mathrm{pH} 4.8$ ) as substrates, respectively. The reaction mixture consisting of $500 \mu \mathrm{L}$ of substrate and $250 \mu \mathrm{L}$ of enzyme solution was incubated at $50{ }^{\circ} \mathrm{C}$ for $1 \mathrm{~h}$. Then $250 \mu \mathrm{L}$ of reaction mixture with $500 \mu \mathrm{L}$ of DNS reagent was mixed and boiled for $5 \mathrm{~min}$. Absorbance at $540 \mathrm{~nm}$ was measured. Blanks contained citrate buffer instead of digestive enzyme solution. One unit of cellulase activity (U/g MMF) was 
defined as the amount of enzyme required for the liberation of $1 \mu \mathrm{mol}$ of glucose per minute under the described conditions.

We assayed lipase activity by the method of Kordel et al. (1991) with slight modifications. The substrate solution was prepared by adding one part of solution A (16.5 mM pnitrophenyl palmitate in isopropanol) into nine parts of solution B $(0.4 \%$ Triton X-100 and $0.1 \%$ gum arabic in $50 \mathrm{mM}$ Tris- $\mathrm{HCl}$ buffer ( $\mathrm{pH} 8.0)$ ) by stirring until fully dissolved. Fifty microliters of enzyme solution was added to $450 \mu \mathrm{L}$ of substrate solution and incubated at $37{ }^{\circ} \mathrm{C}$ for $30 \mathrm{~min}$. Absorbance was read at $405 \mathrm{~nm}$. Blanks contained Tris- $\mathrm{HCl}$ buffer instead of digestive enzyme solution. One unit of lipase activity (U/g MMF) was defined as the amount of enzyme required for the liberation of $1 \mu \mathrm{mol}$ of $p$-nitrophenyl per minute under the described conditions.

\section{Enumeration and isolation of microorganisms}

One-gram sample was homogenized with $9 \mathrm{~mL}$ of $0.85 \%(w / v)$ sterile physiological saline; after serial tenfold dilutions, $100 \mu \mathrm{L}$ of the appropriate aliquot was spread on Luria-Bertani (LB) agar plates and Martin agar plates in triplicate. LB agar plates were used for enumeration of bacterium and incubated at $37{ }^{\circ} \mathrm{C}$ for $24 \mathrm{~h}$. Martin agar plates supplemented with 3,4,5,6-tetrachlorofluorescein $(1.5 \mathrm{mg} / \mathrm{mL})$ were used for counting of fungi and incubated at $30{ }^{\circ} \mathrm{C}$ for $48-72 \mathrm{~h}$. After incubation, plates with 30-300 colonies were enumerated and recorded as colony-forming unit per gram of MMF samples (CFU/g). For isolation of microorganisms, LB medium, Czapek's medium, and Malt extract medium were used for isolation of bacteria, mold, and yeast, respectively.

\section{Extraction of total genomic DNA}

The total genomic DNA of MMF samples made by our lab was extracted by the method previously described (Zhou et al. 1996) with some modifications. The pellet of crude nucleic acids was resuspended in sterile Tris-EDTA (TE) buffer (10 mM Tris-HCl, $1 \mathrm{mM}$ EDTA, pH 8.0), after which it was stored at $-40{ }^{\circ} \mathrm{C}$. The DNA from the pure isolates was extracted using Rapid Bacterial Genomic DNA Isolation Kit (Sangon, Shanghai, China) and Rapid Fungi Genomic DNA Isolation Kit (Sangon, Shanghai, China), respectively.

\section{Molecular identification of isolates}

The primers used in this study are shown in Table 1. The primers 27F (Nakai et al. 2012) and 1401R (Yong et al. 2011) were used to amplify the full length of bacterial $16 \mathrm{~S}$ rDNA. The primers NS1 and Fung (May et al. 2001) were used to amplify the fungal $18 \mathrm{~S}$ rDNA gene. The PCR fragments were ligated with pMD18-T vector (Takara, China), subsequently sequenced by Beijing Huada gene company (Beijing, China), and were identified using BLAST search.

\section{PCR-DGGE analysis}

\section{PCR amplification of $16 S$ and $18 S$ rDNA sequences}

The microbial composition of MMF was investigated by amplifying partial sequences of ribosome encoding genes from the total DNA extracts. For bacteria, the V6-V8 region of the 16S rRNA gene of bacterial groups was amplified using the primers 968F-GC and 1401R (Yong et al. 2011). Amplifications were carried out in a final volume of $50 \mu \mathrm{L}$, containing $5 \mu \mathrm{L}$ of $10 \times$ PCR buffer $\left(\mathrm{Mg}^{2+}\right.$ plus $), 4 \mu \mathrm{L}$ dNTP mixture (2.5 mM each), $0.4 \mu \mathrm{M}$ of each primer, 1.25 units of rTaq polymerase (Takara, Dalian, China), and $1 \mu \mathrm{L}$ of template DNA. The reactions were carried out as follows: initial denaturation at $94{ }^{\circ} \mathrm{C}$ for $4 \mathrm{~min}, 30$ cycles of denaturation at $94{ }^{\circ} \mathrm{C}$ for $40 \mathrm{~s}$, annealing at $55^{\circ} \mathrm{C}$ for $40 \mathrm{~s}$, and extension at $72{ }^{\circ} \mathrm{C}$ for $1 \mathrm{~min}$; and a final extension at $72{ }^{\circ} \mathrm{C}$ for $10 \mathrm{~min}$. For fungi, the approximately 350-bp fragment of the $18 \mathrm{~S}$ rRNA gene was amplified using the primers NS1 and GCFung (May et al. 2001). The amplification program was $94{ }^{\circ} \mathrm{C}$ for $4 \mathrm{~min}$; 30 cycles of denaturation at $94{ }^{\circ} \mathrm{C}$ for $40 \mathrm{~s}$, annealing at $51{ }^{\circ} \mathrm{C}$ for $50 \mathrm{~s}$, and extension at $72{ }^{\circ} \mathrm{C}$ for $50 \mathrm{~s}$; and a final extension step at $72{ }^{\circ} \mathrm{C}$ for $10 \mathrm{~min}$. The sizes and quantities of the PCR products were determined using $2 \%$ agarose gel electrophoresis.

\section{Analysis of PCR products by DGGE}

The DGGE was performed with a DGGE-2401 system (CBS Scientific Company) as described previously (Muyzer and Smalla 1998). Electrophoresis was performed in a $0.75-\mathrm{mm}$ polyacrylamide gel $(8 \%(w / v)$ acrylamide/bisacrylamide $37.5: 1)$ in $1 \times$ TAE buffer ( $40 \mathrm{mM}$ Tris base, $20 \mathrm{mM}$ glacial acetic acid, $1 \mathrm{mM}$ EDTA $0.5 \mathrm{M}, \mathrm{pH} 8.0$ ) at $60^{\circ} \mathrm{C}$. In the case of bacteria, gel electrophoresis was carried out for $17 \mathrm{~h}$ at $80 \mathrm{~V}$ on a $8 \%$ acrylamide/bisacrylamide (37.5:1) gel with a $45-55 \%$ denaturant gradient (100\% denaturant corresponding to $7 \mathrm{M}$ urea and $40 \%(w / v)$ formamide), increasing in the electrophoretic run direction. In the case of fungi, gel electrophoresis was carried out for $17 \mathrm{~h}$ at $80 \mathrm{~V}$ on $8 \%$ acrylamide/bisacrylamide (37.5:1) gel with a 25-35\% denaturant gradient. After electrophoresis, DGGE gels were stained with SYBR Green I. Dominant DGGE bands were excised using sterile blades and washed with sterile distilled water thrice in microtubes, and the DNA was extracted in $50 \mu \mathrm{L}$ of TE buffer overnight at $4{ }^{\circ} \mathrm{C}$. One microliter of eluted DNA was reamplified as described above. The amplified fragments were sequenced by Beijing Huada gene company (Beijing, China). 
Table 1 The primers used for PCR in this study

\begin{tabular}{llll}
\hline Primer & Target & Sequence $\left(5^{\prime}-3^{\prime}\right)$ & Reference \\
\hline $27 \mathrm{~F}$ & Bacteria & AGAGTTTGATCCTGGCTCA & Nakai et al. 2012 \\
1401R & Bacteria & GCGTGTGTACAAGACCC & Yong et al. 2011 \\
968F-GC & Bacteria & $\frac{\text { CGCCCGCCGCGCGCGGCGGGC }}{\frac{\text { GGGGCGGGGGCACGG GGGG }}{\text { AACGCGAAGAACCTTAC }}}$ & Yong et al. 2011 \\
& & GTAGTCATATGCTTGTCTC & May et al. 2001 \\
NS1 & Fungi & $\frac{\text { CGCCCGCCGCGCCCCGCGCCC }}{\text { GGCCCGCCGCCCCCGCCCC }}$ & May et al. 2001 \\
GCFung & Fungi & ATTCCCCGTTACCCGTTG & \\
& & &
\end{tabular}

The GC clamp is underlined

\section{Sequencing and phylogenetic analysis}

Obtained sequences were compared to the GenBank database with the BLAST program. The phylogenetic tree was constructed using the neighbor-joining method by the software MEGA 5.0 with 1,000 bootstraps. Band intensities were calculated using the software BIO-1D, and the relative band intensities were calculated by dividing the peak area of a band by the sum of the peak areas of all bands in a lane.

Nucleotide sequence accession numbers

The sequences reported in this study were deposited in GenBank. The sequences obtained from DGGE are under accession numbers KF411361 to KF411383, and those of the isolates are under accession numbers KF411346 to KF411360.

\section{Results}

Digestive enzyme assay

We investigated the changes of four digestive enzymes during MMF fermentation process (Fig. 1a). The four digestive enzymes included amylase, cellulase, lipase, and protease. With the exception of protease, the activities of the three other digestive enzymes showed a similar trend. The filter paper activity (FPA) and the activities of amylase, carboxymethyl cellulase (CMCase), and lipase significantly increased during the first 4 days and reached a peak at day 4 (up to 2.2, 304.7, 3.6, and $117.2 \mathrm{U} / \mathrm{g}$, respectively), indicating that some microorganisms rapidly increased in the early fermentation stage and produced a large number of enzymes. Afterwards, the amylase activity slightly decreased (249 U/g) until the end of the fermentation process. Unlike amylase, FPA, CMCase activity, and lipase activity significantly decreased from day 4 to day 5 , then slightly decreased (up to $0.9,1.8$, and $43.2 \mathrm{U} / \mathrm{g}$, respectively) until the end of the fermentation. We supposed that the environment was not suitable for the growth of some microorganisms or antagonism between various microorganisms inhibited the metabolism of some microorganisms, thus resulting in a decline of enzyme activities. However, the protease activity exhibited a different trend compared with the abovementioned enzymes. Its activity slowly increased in the first 4 days of fermentation and, subsequently, exponentially

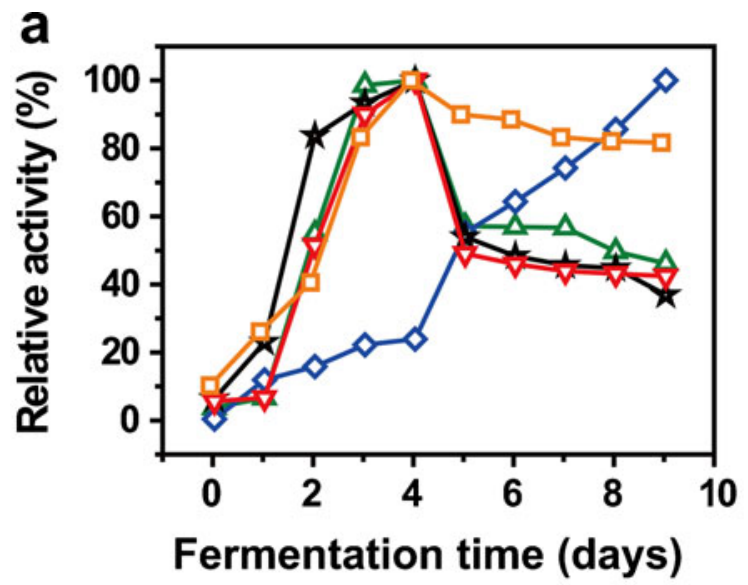

b

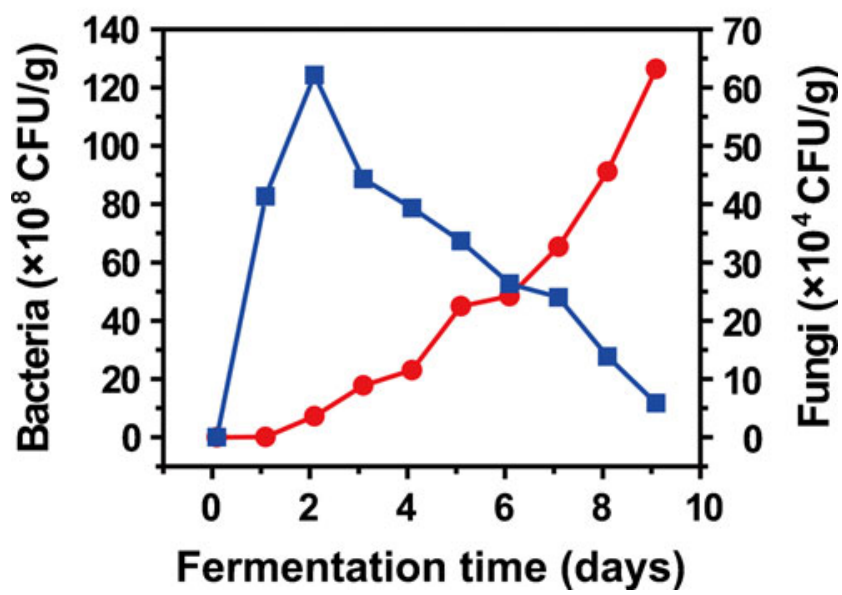

Fig. 1 Changes of the relative activities of digestive enzymes (a) and bacteria and fungi cell counts (b) during MMF fermentation process. Orange open square, amylase; black open pentagram, lipase; green open upper triangular, CMCase; red open lower triangular, FPA; blue open diamond, protease; blue filled square, total bacteria; red filled circle, total fungi 
increased up to $777.9 \mathrm{U} / \mathrm{g}$ until the end of fermentation. The protease activity and total fungi counts showed a similar trend (Fig. 1b), indicating that the protease that we measured was mainly produced by fungi during the fermentation process.

Cultivable microbial counting during MMF fermentation process

The statistical analysis results of cultivable microbial dynamic changes were illustrated in Fig. 1b. The quantity of bacteria and fungi showed different trends during the fermentation process. Bacteria numbers significantly increased for the first 2 days, reached a peak $\left(1.2 \times 10^{10} \mathrm{CFU} / \mathrm{g}\right)$ at day 2 , and then decreased. Fungi counts increased slowly for the first 4 days, then rapidly increased and obtained the maximal counts $(6.3 \times$ $10^{5} \mathrm{CFU} / \mathrm{g}$ ) at the end of the fermentation.

\section{DGGE analysis of bacteria}

Bacterial DGGE patterns and the dynamic changes of the relative intensities of DGGE bands are shown in Fig. 2. A total of 14 bands were detected (Fig. 2a). A clear reduction of

a

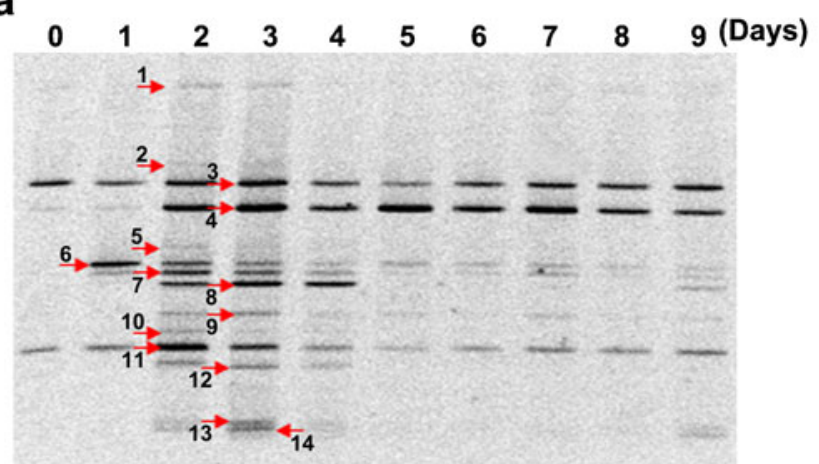

b
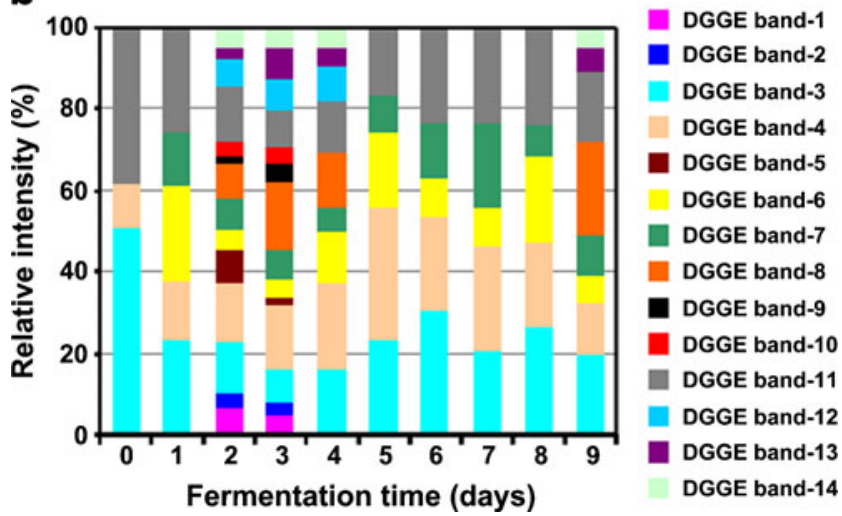

Fig. 2 PCR-DGGE profile (a) of the bacterial community and relative intensity (b) based on the band intensities of bacterial DGGE community profile from MMF samples during fermentation (bands that were excised for sequence analysis are numbered) bacterial diversity was shown from day 4 and remained stable in the late period of the fermentation. The bands 3,4 , and 11 could be detected throughout the fermentation process and were dominant bands during all MMF fermentation process with highest relative intensity (Fig. 2b). The results indicated that these three bacteria were involved in all MMF fermentation process and were the dominant bacteria during the fermentation process. Some new bands appeared at day 2 and day 3 , then disappeared at day 5 , and the results showed a similar trend with total bacteria counts, which indicated that the intensity of DGGE bands can reflect the changes of microbial community but were also restricted by total viable counts.

\section{DGGE analysis of fungi}

Fungal DGGE profile and relative intensity dynamics of DGGE bands are shown in Fig. 3. Figure 3a showed that the fungi were simple. A total of nine bands were detected. The bands (1 and 6) had the highest relative intensity (Fig. 3b), which can indicate that they were the dominant fungi during fermentation.

a
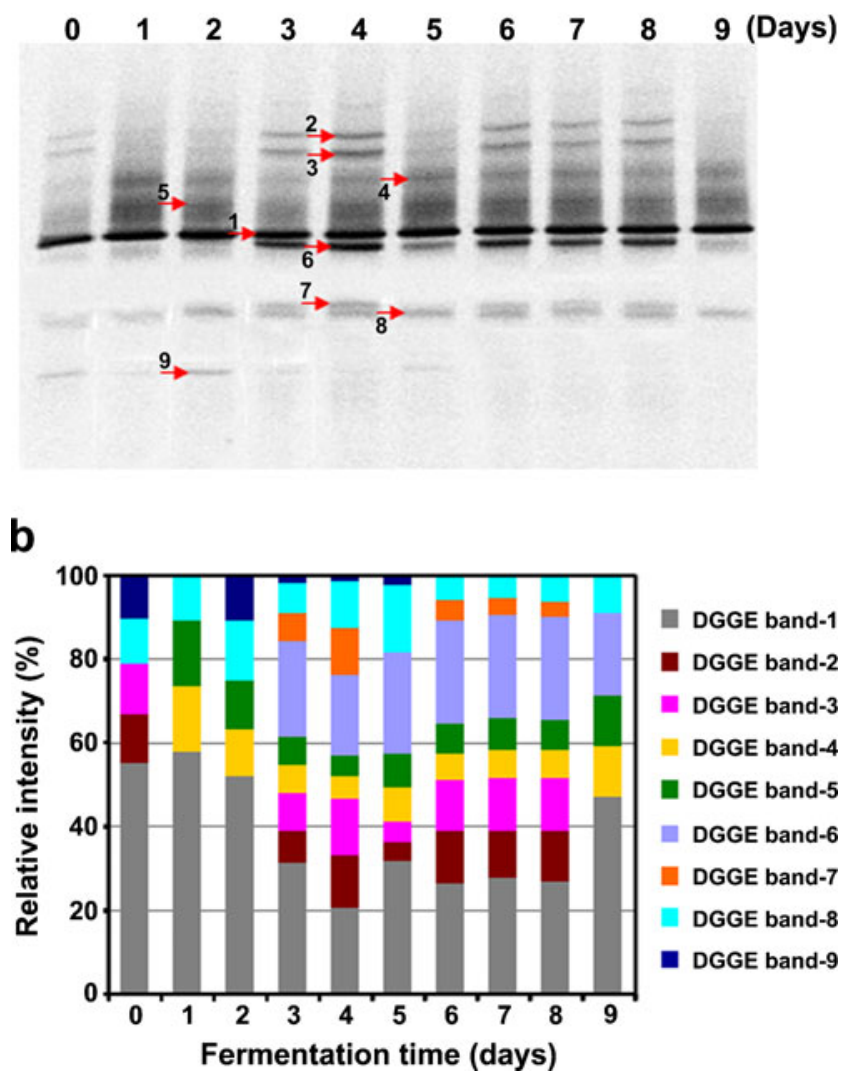

Fig. 3 PCR-DGGE profile (a) of the fungal community and relative intensity (b) based on the band intensities of fungal DGGE community profile from MMF samples during fermentation (bands that were excised for sequence analysis are numbered) 
Isolation and molecular identification of pure cultures

One hundred seventy pure cultures were isolated from the ten samples collected during MMF fermentation process. The bacteria included 91 strains and the fungi included 79 strains. Sequences obtained from isolates were compared to the GenBank database with the BLAST program. The 170 isolates were identified to 15 species (Table 2). Eight of them were bacteria, five of them were molds, and two of them were yeasts. The results indicated that the bacteria that existed during MMF fermentation process were closely related to the genera Enterobacter, Klebsiella, Pseudomonas, and Acinetobacter, spanning the families Enterobacteriaceae, Moraxellaceae, and Pseudomonadaceae. The molds were affiliated with the genera Amylomyces and Mucor, belonging to family Mucoraceae. The yeasts were close to the genera Saccharomyces and Rhodotorula, spanning the families Saccharomycetaceae and Cryptococcaceae. These results were partly coincidental with those obtained from DGGE analysis.

\section{Phylogenetic analysis}

Bacterial phylogenetic analysis was done based on the sequences of 14 DGGE bands and eight bacterial isolates (Fig. 4). The phylogenetic tree showed that bacteria were grouped into five families. Bands 1-6 and 9, and pure isolates B (1-4), B-8 were classified as Enterobacteriaceae. Pure isolate B-7 and band 7 were identified as Moraxellaceae and Lactobacillaceae, respectively. Bands 8, 10, and 11, together with pure isolates B-5 and B-6 were relatives of Pseudomonadaceae. Bands 12, 13, and 14 were detected as Bacillaceae. The Enterobacteriaceae accounted for $50 \%$ of the total bacteria counts, and Pseudomonadaceae and Bacillaceae accounted for $21 \%$ of the total bacteria counts, respectively. The results indicated that the family Enterobacteriaceae was the predominant bacteria during MMF fermentation process.

Fungal phylogenetic analysis including the sequences of fungal DGGE and fungal isolates was performed to reveal the species and distribution of various fungi (Fig. 5). The fungi were grouped into three families. Bands 2,3 , and 5-7, and pure isolates F (1-5) were classified as Mucoraceae. Pure isolate F-7 and band 9 were relatives of Cryptococcaceae. Bands 1,4 , and 8 , together with pure isolate F-6, were detected as Saccharomycetaceae. The results indicated that Mucoraceae was the dominant group of fungi and played an important role during MMF fermentation.

\section{Discussion}

MMF fermentation is a spontaneous process and involves a succession of changes of microbial community. The study on microbial diversity and dynamic changes during MMF fermentation cannot only be conducive to elucidate the fermentation mechanism and to optimize the fermentation process but also has

Table 2 Alignment of the cultivable bacteria and fungi to its most similar GenBank sequences

\begin{tabular}{|c|c|c|c|c|c|}
\hline $\begin{array}{l}\text { Sequenced } \\
\text { strains }\end{array}$ & $\begin{array}{l}\text { Length of } 16 \mathrm{~S} \text { or } 18 \mathrm{~S} \\
\text { rDNA fragments (bp) }\end{array}$ & $\begin{array}{l}\text { GenBank } \\
\text { accession number }\end{array}$ & $\begin{array}{l}\text { Aligned site in } \\
\text { GenBank sequence }\end{array}$ & $\begin{array}{l}\text { Similarity } \\
\text { rate }(\%)\end{array}$ & Source of the most similar GenBank sequence \\
\hline B-1 & $1,397^{\mathrm{a}}$ & DQ919062.1 & $1-1359$ & 99 & Enterobacter cowanii strain 6L \\
\hline B-2 & $1,354^{\mathrm{a}}$ & EF120473.1 & $1-1306$ & 99 & Enterobacter cloacae \\
\hline B-3 & $1,374^{\mathrm{a}}$ & KC455426.1 & $9-1321$ & 99 & Klebsiella sp. SFR-117 \\
\hline B-4 & $1,358^{\mathrm{a}}$ & JX081544.1 & $1-1317$ & 99 & Enterobacter sp. M3(2012) \\
\hline B-5 & $1,353^{\mathrm{a}}$ & FJ972539.1 & $4-1313$ & 99 & Pseudomonas fulva 67 \\
\hline B-6 & $1,349^{\mathrm{a}}$ & EU489564.1 & $1-1304$ & 99 & Pseudomonas sp. 471-1 \\
\hline B-7 & $1,360^{\mathrm{a}}$ & KC422705.1 & $2-1308$ & 99 & Acinetobacter johnsonii strain zhy 33 \\
\hline B-8 & $1,348^{\mathrm{a}}$ & GU086162.1 & $37-1343$ & 99 & Enterobacter sp. PR5 \\
\hline $\mathrm{F}-1$ & $355^{\mathrm{b}}$ & EU736294.1 & $1-337$ & 99 & Amylomyces rouxii strain FSU761 \\
\hline $\mathrm{F}-2$ & $355^{\mathrm{b}}$ & HM641689.1 & $25-377$ & 99 & $\begin{array}{l}\text { Mucor circinelloides f. circinelloides strain } \\
\text { WA0000017591 }\end{array}$ \\
\hline F-3 & $355^{\mathrm{b}}$ & AJ271061.1 & $611-964$ & 99 & Mucor racemosus \\
\hline $\mathrm{F}-4$ & $355^{\mathrm{b}}$ & JN939019.1 & $1-322$ & 99 & M. circinelloides strain DAOM 225703 \\
\hline F-5 & $355^{\mathrm{b}}$ & HQ845293.1 & $1-307$ & 100 & M. circinelloides strain NRRL 54372 \\
\hline F-6 & $349^{\mathrm{b}}$ & GU266277.1 & $17-365$ & 100 & Saccharomyces arboricola strain AS 2.3317 \\
\hline F-7 & $344^{\mathrm{b}}$ & HQ420261.1 & $1-347$ & 99 & Rhodotorula glutinis \\
\hline
\end{tabular}

$B-1$ to $B-8$ the strains of the cultivable bacteria, $F-1$ to $F-7$ the strains of the cultivable fungi

${ }^{\text {a }}$ Length of $16 \mathrm{~S}$ rDNA fragments

${ }^{\mathrm{b}}$ Length of $18 \mathrm{~S}$ rDNA fragments 
Fig. 4 Phylogenetic tree based on sequences of the bacteria from MMF. $B$ isolates of bacteria. The numbers given in the branches are the bootstrap values after 1,000 repetitions

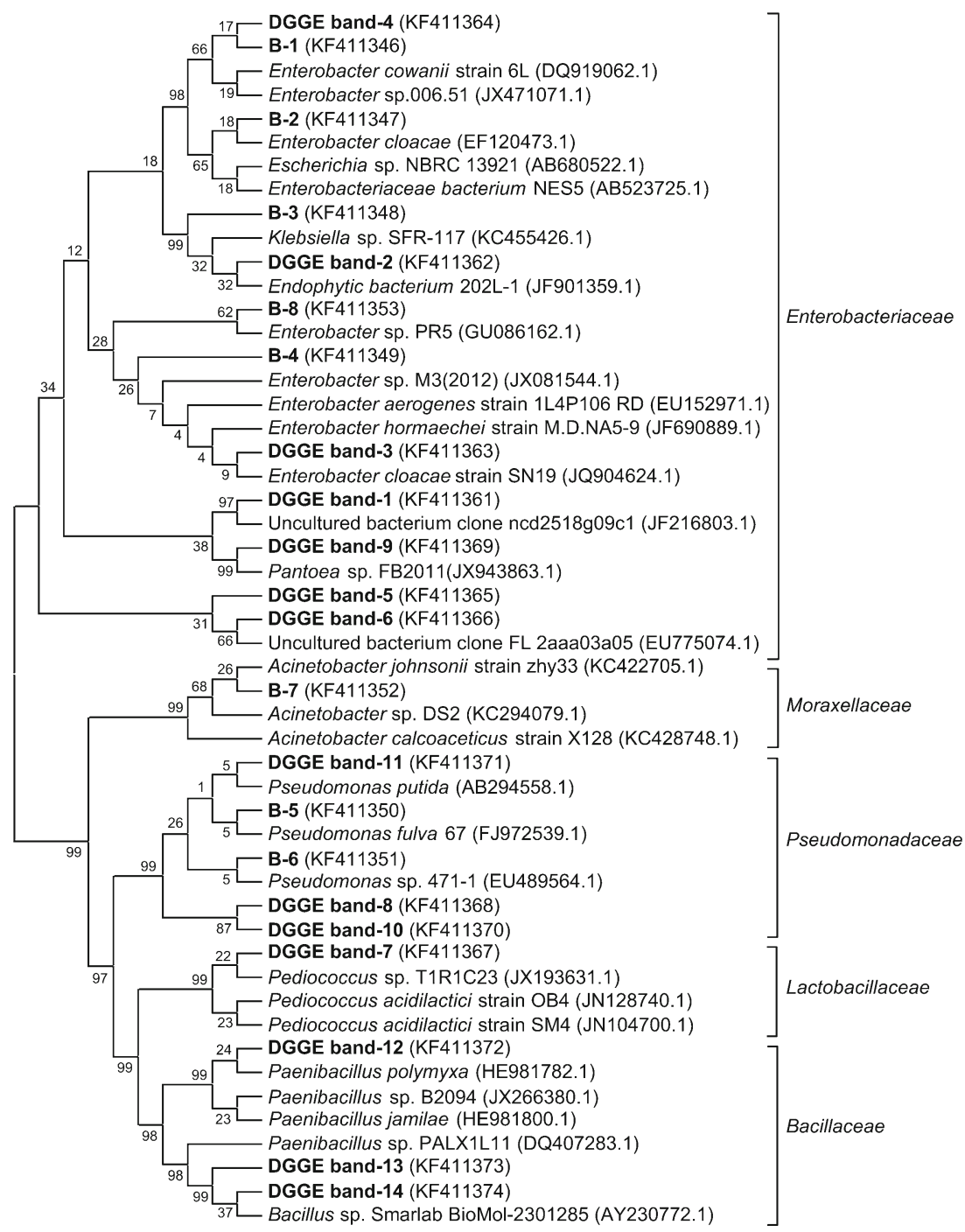

significant potential for controlling the fermentation of MMF. In this study, the culture-dependent method and cultureindependent method (PCR-DGGE) were used to analyze bacterial and fungal communities during MMF fermentation process. PCR-DGGE can provide a broad overview within a short time, making it an effective supplement to culturing methods. Although this technique has advantages such as reliability, high throughput, and reproducibility (Muyzer et al. 1993), it still has some drawbacks such as its limited data on the microbes with higher concentration (Ruiz et al. 2010) and not providing accurate quantitative data liking plate counting. To obtain more overall profiles of microbial community during MMF fermentation, we also used a culturedependent method. In this study, we selected three media (LB medium, Czapek's medium, and Malt extract medium) to isolate microorganisms of MMF referring to the results of PCR-DGGE. This can reduce the blindness of directly using traditional microbiological methods and improve targeting.

DGGE results showed that the bacteria were more complex than fungi. Fourteen bands were obtained and identified from bacterial DGGE profile, and a total of nine bands were detected for fungi. Phylogenetic analysis indicated that Enterobacter sp., Pediococcus sp., and Pseudomonas sp. were the main representative bacteria during MMF fermentation process; the dominant fungi were Mucor sp. and Saccharomyces sp..

One hundred seventy isolates were isolated from the ten samples collected during MMF fermentation process. The 170 isolates were identified to 15 species and closely related to the genera Enterobacter, Klebsiella, Acinetobacter, Pseudomonas, Mucor, Amylomyces, Saccharomyces, and Rhodotorula. The results were partially consistent with those reported by Gao and Jia (2002), who isolated Bacillus sp., Mucor sp., and Aspergillus sp. from MMF.

The culturing results revealed partially coincident results with PCR-DGGE results. The endophytic bacterium, Uncultured bacterium clone, Pantoea sp., Pediococcus sp., Paenibacillus sp., Bacillus sp., Uncultured eukaryote clone, and Uncultured fungus clone were only detected by PCR-DGGE analysis; this could be due to the inability of selective media to provide specific growth requirements. The Klebsiella sp., 
Fig. 5 Phylogenetic tree based on sequences of the fungi from MMF. $F$ isolates of fungi. The numbers given in the branches are the bootstrap values after 1,000 repetitions

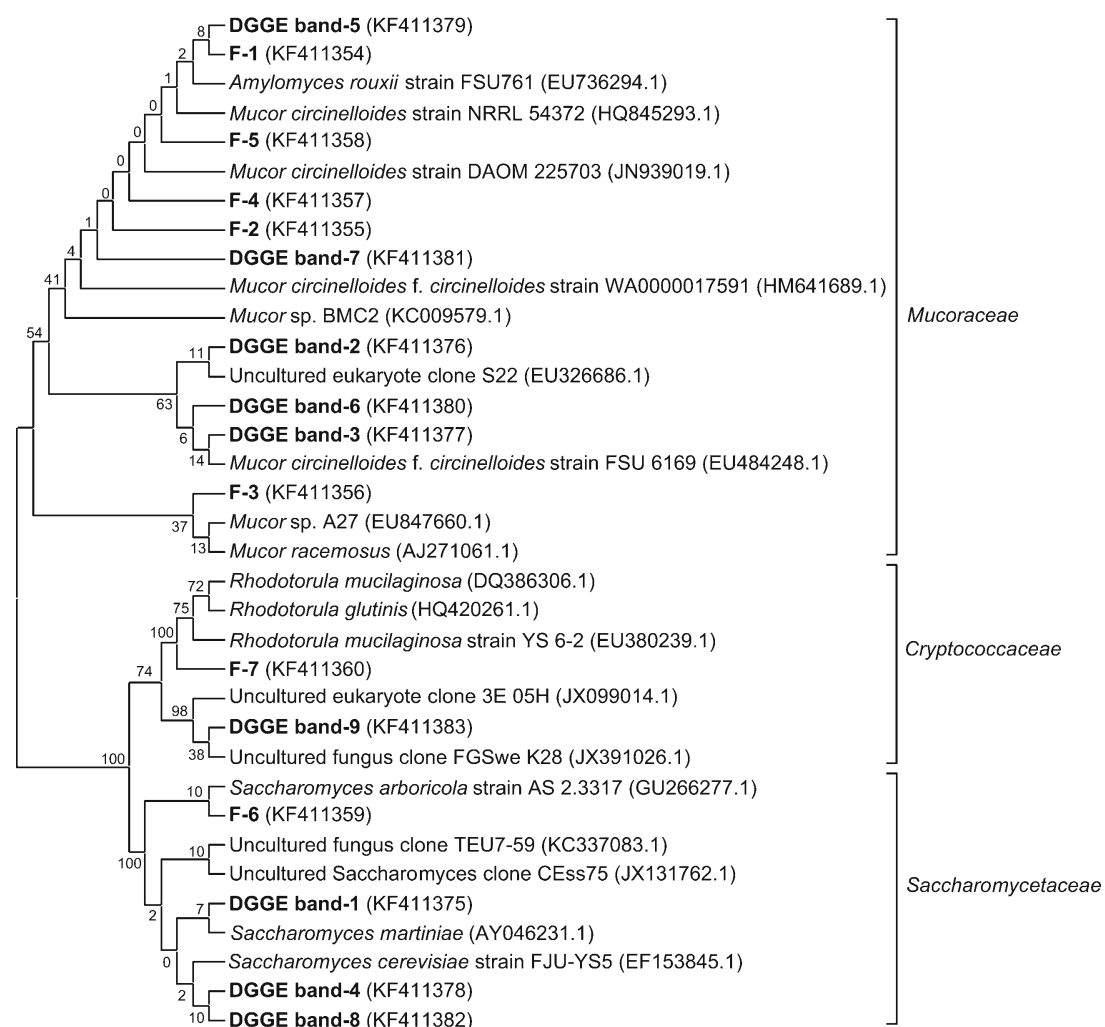

Acinetobacter sp., and Rhodotorula sp. were only identified by culture-dependent method analysis, owing to the low concentrations of these microorganisms. Generally, only the microbe populations that make up $1 \%$ or more of the total community might be detected by DGGE. The Enterobacter sp., Pseudomonas sp., Amylomyces sp., Mucor sp., and Saccharomyces sp. were detected by both methods.

Among the bacteria found in MMF, Enterobacter sp., Pseudomonas sp., and Paenibacillus sp. are amylaseproducing microorganisms (Kumar and Das 2000; Valente et al. 2006; Rajesh et al. 2013). Enterobacter sp. and Pseudomonas sp. can also produce lipase (Sinkūniene et al. 2008; Kordel et al. 1991). Pediococcus sp. is commonly found in fermented dairy products, fermented vegetables, and meat (Barros et al. 2001) and has emerged as a potential probiotic bacterium. Keuth and Bisping (1994) showed that the bacterium Klebsiella can produce Vitamin $\mathrm{B}_{12}$. As we all know, Mucor sp. and Saccharomyces sp. are important species of the fermentation industry and food processing industry. The Amylomyces sp. and Mucor sp. can produce numerous extracellular enzymes, such as protease, amylase, cellulase, and lipase (Marcial et al. 2011; Mohapatra et al. 1998; Coca and Dustet 2006; Alves et al. 2005; Mohamed et al. 2011). The Saccharomyces sp. can produce protease and amylase (Haq et al. 2002; Moehle et al. 1987). The MMF fermentation process is a biotransformation process, microorganisms play an important role, and they have both individual function and interaction in the process. Microbial growth and metabolism also can more drastically improve herb efficacy, reduce toxicity, and expand indications than physical or chemical methods and can also improve the extraction, absorption, and utilization rate of the active ingredient (Zhang et al. 2012b). Extracellular enzymes such as cellulase can decompose cell wall of medicinal plants, so that the active ingredient of medicinal plants is fully released, and ultimately enhance herb efficacy (Yang et al. 2005).

On the MMF fermentation mechanism, the results of bacteria and fungi counts of MMF fermentation showed that bacteria was the dominant microbe from day 0 to day 4 , and fungi was the dominant microorganism from day 5 to day 9 (Fig. 1b). The DGGE profiles showed the bacteria were active during the first 4 days, and the fungi were active during the last 5 days. These results indicated that MMF fermentation process consisted of two stages, the pre-fermentation stage ( $0-4$ days) dominated by bacteria and the post-fermentation stage (5-9 days) dominated by fungi.

In conclusion, this study provided a more comprehensive knowledge on microbes and digestive enzymes during MMF fermentation. The results showed that Enterobacter sp., Pediococcus sp., Pseudomonas sp., Saccharomyces sp., and Mucor sp. were dominant microbes during the fermentation process. MMF fermentation included two stages: a pre-fermentation stage dominated by bacteria and a postfermentation stage dominated by fungi. PCR-DGGE results can be used as a reference for pure culture. However, in order to determine the exact functional microorganisms during 
MMF fermentation, more studies in detail should be made further in the future.

Acknowledgments The study was financially supported by the General Programs of the National Natural Science Foundation of China (81072564) and by the Key Project of Science and Technology Department of Jilin Province of China (20090945 and 20130727036YY).

Open Access This article is distributed under the terms of the Creative Commons Attribution License which permits any use, distribution, and reproduction in any medium, provided the original author(s) and the source are credited.

\section{References}

Albano H, Henriques I, Correia A, Hogg T, Teixeira P (2008) Characterization of microbial population of 'Alheira' (a traditional Portuguese fermented sausage) by PCR-DGGE and traditional cultural microbiological methods. J Appl Microbiol 105:2187-2194

Alves MH, Campos-Takaki GM, Okada K, Pessoa IHF, Milanez AI (2005) Detection of extracellular protease in Mucor species. Rev Iberoam Micol 22:114-117

Barros RR, Carvalho MDGS, Peralta JM, Facklam RR, Teixeira LM (2001) Phenotypic and genotypic characterization of Pediococcus strains isolated from human clinical sources. J Clin Microbiol 39: $1241-1246$

Coca J, Dustet JC (2006) Expression and characterization of lipase produced by Mucor griseocyanus. Biotecnol Apl 23:224-228

Endo A, Okada S (2005) Monitoring the lactic acid bacterial diversity during shochu fermentation by PCR-denaturing gradient gel electrophoresis. J Biosci Bioeng 99:216-221

Fontana C, Cappa F, Rebecchi A, Cocconcelli PS (2010) Surface microbiota analysis of Taleggio, Gorgonzola, Casera, Scimudin and Formaggio di Fossa Italian cheeses. Int J Food Microbiol 138:205-211

Gao H, Jia TZ (2002) The research progress of Massa Medicata Fermentata. Lishizhen Med Materia Medica Res 8:491-493 (in Chinese)

Ghose TK (1987) Measurement of cellulase activities. Pure App Chem 59:257-268

Haq IU, Abdullah R, Ashraf H, Shah AH (2002) Isolation and screening of fungi for the biosynthesis of alpha amylase. Int J Biot 1:61-66

Hu J, Yang XD, Xia QP, Cai ZW (2004) Research on the microorganism in the traditional Chinese medicine 'Shenqu'. J Mudanjiang Med Coll 2:19-20 (in Chinese)

Hugenholtz P, Goebel BM, Pace NR (1998) Impact of cultureindependent studies on the emerging phylogenetic view of bacterial diversity. J Bacteriol 180:4765-4774

Keuth S, Bisping B (1994) Vitamin $B_{12}$ production by Citrobacter freundii or Klebsiella pneumoniae during tempeh fermentation and proof of en-terotoxin absence by PCR. Appl Environ Microbiol 60:1495-1499

Kordel M, Hofmann B, Schomburg D, Schmid RD (1991) Extracellular lipase of Pseudomonas sp. strain ATCC 21808: purification, characterization, crystallization, and preliminary X-ray diffraction data. J Bacteriol 173:4836-4841

Kumar N, Das D (2000) Production and purification of a-amylases from hydrogen producing Enterobacter cloacae II-BT 08. Bioprocess Eng 23:205-208

Marcial J, Perez de los Santos AI, Fernandez FJ, Diaz-Godinez G, MontielGonzalez AM, Tomasini A (2011) Characterization of an aspartic protease produced by Amylomyces rouxii. Rev Mex Ing Quim 1:9-16

May LA, Smiley B, Schmidt MG (2001) Comparative denaturing gradient gel electrophoresis analysis of fungal community associated with whole plant corn silage. Can J Microbiol 47:829-841
Miller GL (1959) Use of dinitrosalicylic acid reagent for the determination of reducing sugar. Anal Chem 31:426-428

Moehle CM, Aynardi MW, Kolodny MR, Park FJ, Jones EW (1987) Protease B of Saccharomyces cerevisiae: isolation and regulation of the PRBI Structural Gene. Genetics 115:255-263

Mohamed SA, Abdel-Mageed HM, Tayel SA, El-Nabrawi MA, Fahmy AS (2011) Characterization of Mucor racemosus lipase with potential application for the treatment of cellulite. Process Biochem 46: 642-648

Mohapatra BR, Banerjee UC, Bapuji M (1998) Characterization of a fungal amylase from Mucor sp. associated with the marine sponge Spirastrella sp. J Biotechnol 60:113-117

Muyzer G, Smalla K (1998) Application of denaturing gradient gel electrophoresis (DGGE) and temperature gradient gel electrophoresis (TGGE) in microbial ecology. Antonie van Leeuwenhoek 73:127-141

Muyzer G, de Waal EC, Uitterlinden AG (1993) Profiling of complex microbial populations by denaturing gradient gel electrophoresis analysis of polymerase chain reaction-amplified genes coding for 16S rRNA. Appl Environ Microbiol 59:695-700

Nakai R, Abe T, Baba T, Imura S, Kagoshima H, Kanda H, Kanekiyo A, Kohara Y, Koi A, Nakamura K, Narita T, Niki H, Yanagihara K, Naganuma T (2012) MicroXorae of aquatic moss pillars in a freshwater lake, East Antarctica, based on fatty acid and 16S rRNA gene analyses. Polar Biol 35:425-433

Rajesh T, Kim YH, Choi YK, Jeon JM, Kim HJ, Park SH, Park HY, Choi KY, Kim H, Kim HJ, Lee SH, Yang YH (2013) Identification and functional characterization of an a-amylase with broad temperature and $\mathrm{pH}$ stability from Paenibacillus sp. Appl Biochem Biotechnol 170:359-369

Ruiz P, Seseña S, Izquierdo PM, Palop ML (2010) Bacterial biodiversity and dynamics during malolactic fermentation of Tempranillo wines as determined by a culture-independent method (PCR-DGGE). Appl Microbiol Biotechnol 86:1555-1562

Sinkūniene D, Kiriliauskaitė V, Bendikienė I, Juodka B (2008) Properties and immobilization of Enterobacter aerogenes 13 lipase. Roumanian Biotechnol Lett 13:1-8

Tao CX (2000) The tonifying spleen and digestion of herbal leaven. China J Tradit Chin Med 3:33-33

Valente JJ, Fryksdale BG, Dale DA, Gaertner AL, Henry CS (2006) Screening for physical stability of a Pseudomonas amylase using self-interaction chromatography. Anal Biochem 357:35-42

Wang HY, Gao YB, Fan QW, Xu Y (2011) Characterization and comparison of microbial community of different typical Chinese liquor Daqus by PCR-DGGE. Lett Appl Microbiol 53:134-140

Wang HY, Gao WY, Zhang LX (2012) Influence of different processing techniques of Massa Medicata Fermentata on their amylase activity. China J Chin Materia Medica 37:2084-2087

Wu TX, Wang N, Zhang Y, Xu XB (2013) Advances in the study on microbial fermentation and transformation of traditional Chinese medicine. Afr J Microbiol Res 7:1644-1650

Yang JX, Cai JP, Zhu L (2005) The application of cellulase in the Chinese medicine ingredient extraction. Chin Herb Med 1:64-67

Yong XY, Cui YQ, Chen LH, Ran W, Shen QR, Yang XM (2011) Dynamics of bacterial community during solid-state fermentation using agro-industrial wastes to produce poly- $\gamma$-glutamic acid, revealed by real-time PCR and denaturing gradient gel electrophoresis (DGGE). Appl Microbiol Biotechnol 92:717-725

Zhang LX, Gao WY, Wang HY (2012a) Identification of microorganism from traditional Chinese medicine Massa Medicata Fermentata. China J Chin Materia Medica 37:1928-1931 (in Chinese)

Zhang LX, Gao WY, Wang HY (2012b) Review of traditional Chinese medicine processed by fermentation. China J Chin Materia Medica 24:3695-3700

Zhou JZ, Bruns MA, Tiedje JM (1996) DNA recovery from soils of diverse composition. Appl Environ Microbiol 62:316-322 